\title{
ON THE CONTINUITY OF THE GROUP INVERSE
}

\author{
Julio BeníteZ AND XiAOJi LiU
}

Abstract. Let $\left\{A_{m}\right\}_{m=1}^{\infty}$ be a sequence of complex group invertible matrices that converges to $A$. We characterize when $A$ is group invertible and $\left\{A_{m}^{\#}\right\}_{m=1}^{\infty}$ converges to $A^{\#}$ in terms of the canonical angles between $A_{m}$ and $A_{m}^{*}$, where $X^{\#}$ denotes the group inverse of the matrix $X$. We compare this characterization with some known characterizations of the continuity of the Drazin inverse.

Mathematics subject classification (2010): 15A09.

Keywords and phrases: Continuity of the group inverse, canonical angles, generalized inverses.

\section{REFERENCES}

[1] A. Ben-Israel, T. N. E. Greville, Generalized Inverses: Theory and Applications, WileyInterscience New York, 1974, second ed. Springer, New York, 2002.

[2] J. BeníTEZ, A new decomposition for square matrices, Electron. J. Linear Algebra 20 (2010), 207-225.

[3] S. L. CAmpbell, C. D. Meyer, Generalized inverses of linear transformations, Dover, 1991.

[4] D. S. DJORDJEVIĆ, V. RAKOČEVIĆ, Lectures on generalized inverses, University of Niš, 2008.

[5] D. T. KaTO, Perturbation theory for linear operators, Springer, New York, 1966.

[6] S. Izumino, Convergence of generalized inverses and spline projectors, J. Approx. Theory 38 (1983), 269-278.

[7] J. Koliha, V. RakočEvić, Continuity of the Drazin inverse II, Stud. Math. 131, 2 (1998), 167-177.

[8] R. Penrose, A generalized inverse for mtrices, Proc. Cambridge Phil. Soc. 51 (1953), 406-413.

[9] G. W. STEWART, On the continuity of the generalized inverses, SIAM, J. Appl. Math. 17 (1969), 33-45.

[10] H. K. Wimmer, Canonical angles of unitary spaces and perturbations of direct complements, Linear Algebra Appl. 287 (1999), 373-379. 